\title{
Forest Activity Classification System of Small Watershed Area using GIS (II) -Forest activity classification system in case of raster-
}

\author{
Hisaaki Kamioka*, Nobuyuki Abe* and Ryo Benitani*
}

\begin{abstract}
A method to evaluate the forest function in a small watershed area in every raster was shown. Concurrently, the influence of the raster size on forest function evaluation was analyzed by changing the raster size $(10 \mathrm{~m}, 20 \mathrm{~m}$, $50 \mathrm{~m})$. As a result of comparison with function classification in a small sub-compartment unit, from conversion accuracy of vector information and presumed result of inclination angle, it was considered that a raster size of $10 \mathrm{~m} \times 10 \mathrm{~m}$ is optimum for forest function evaluation in a small watershed area. As for comparison of a forest in a small sub-compartmentunit and raster unit, the areas for the timber production, public health and recreation, and selection cutting water source conservation functions increased. Conversely, a decrease in the areas for erosion production and reserved water source conservation functions was recognized.
\end{abstract}

Keyword: forest activity, raster, GIS

\section{INTRODUCTION}

In the preceding analysis, a system to evaluate forest function in a small sub-compartment unit used most widely in actual work activities was evaluated. The topographic and site merit information used for the function evaluation were calculated from DTM, and then these were averaged in each small sub-compartment and utilized. However, in a small sub-compartment, various topographic and site merit information is contained and only a standardized evaluation can be performed using the averaged information. Accordingly, by using GIS (Terra Soft), an analytical method making the best of the distinctive features of the raster type data was investigated. The raster data is a advantaged model. It has a simple structure and overlay operations are easily and efficiently implemented. (ARONOFF 1989) Accordingly, by generating the rasters, and furthermore by having the individual rasters contain information on topography, site merit and stand a method to evaluate forest function was investigated.

* Faculty of Agriculture, Niigata University, 8050 Ikarashi Ninocho, Niigata 950-21 Japan

\section{SMALL WATERSHED AREA AS AN OBJECT}

As in the preceding report,the 59th forest compartment (246ha) of the Nioujidake Group, under the jurisdiction of the Shibata National Forestry Bureau, was made a watershed area and used as the object of this study. The Mizutanisawa flows in the approximate center of this watershed area. About $1 / 3$ of the stand is composed of a man-made sugi (Cryptomeria Japonica D.DoN) forest, and the balance is composed of natural forest. As for a status of the natural forest, downstream of the Mizutanisawa, many trees with a relatively small diameter, such as the konara (Quercus serrata THUNB.), kuri (Castanea crenata SiEB. et ZuC.), buna (Fagus crenata BLUME) and so forth are distributed, while the upstream area is plotted by trees with a large diameter, such as tochinoki (Aesulus turbinata Blume), itayakaede (Acer mono MAXim.) and so forth. Man-made sugi forest is relatively good in terms of growth, and consequently magnificent 80 years old forest still remains. In addition, because this watershed area is located at a site about $10 \mathrm{~km}$ from Shibata City and is adjacent to the Tainai-Niouji Prefectural Natural Park, its utilization as a natural recreational forest can be expected. 


\section{METHODS}

As for forest function, according to the standards shown in the preceding report, by using (Terra Soft), a function evaluation through raster was investigated. The map information input into GIS are forest subcompartment, contour line, forest road, ridge and water system. In addition, the stand information can be obtained by superimposing the rasters on the sub-compartments, and the inclination angle is calculated by each raster size (Essential Planning Systems Limited 1992). Forest activity is evaluated using the raster information. The results are investigated, based on comparison with forest function division by preceding reports, and the difference in raster size. The flow of the analysis and investigation are shown in Fig. 1.

\section{Investigation of Raster Size}

An analysis can be done by setting the raster size freely in case of GIS. However, in a topographic analysis, raster size will be an important point at issue. Although it is anticipated that the topographic data can be expressed in more detail with a smaller raster size, when the altitude interval of the input contour line is considered, making the size smaller is not necessarily connected to an improvement in accuracy.

In this report, raster of $20 \mathrm{~m} \times 20 \mathrm{~m}$ utilized for calculating the average inclination angle in No. I report was set as a standard, with a smaller raster $(10 \mathrm{~m} \times 10 \mathrm{~m})$ and a larger raster $(50 \mathrm{~m} \times 50 \mathrm{~m})$ also being set. The forest function evaluation was carried out using these 3 sizes, and an optimum raster size investigated.
Forest Function Evaluation by Raster

A forest function was evaluated according to the standards shown in the preceding report.

1. Timber production forest - Man-made forest with 1st class of site merit and above 3rd class of site class.

2. Erosion protection forest - Natural forest and man-made forest whose distance from the ridge is $100 \mathrm{~m}$ and whose inclination angle is greater than $30^{\circ}$, or whose inclination angle is greater than $30^{\circ}$.

3. Water source conservation forest - Natural forest and man-made forest whose distance from the water system is $100 \mathrm{~m}$, or whose distance from the ridge or water system is within $100 \mathrm{~m}$, and whose inclination angle is less than $30^{\circ}$, or with an inclination angle is less than $30^{\circ}$. Stands more than $50 \mathrm{~m}$ from the water system, were classified into 2 types as described below.

3-A) Reserved water source conservation forest - In the stand mentioned above, the stand volume per ha is less than $150 \mathrm{~m} 3$.

3-B) Selection cutting water source conservation forest In the stand mentioned above, the stand volume is greater than $150 \mathrm{~m}^{3}$.

4. Public health and recreational forest - Natural forest and man-made forest whose distance from the water system is within $100 \mathrm{~m}$, or whose distance from the ridge or water system is within $100 \mathrm{~m}$, and inclination angle is less than $30^{\circ}$, or whose inclination angle is less than $30^{\circ}$. Of these, the distance of the stand from the water system is within $50 \mathrm{~m}$.

As mentioned above, through raster analysis, forest function was classified into 4 functions and 5 kinds.

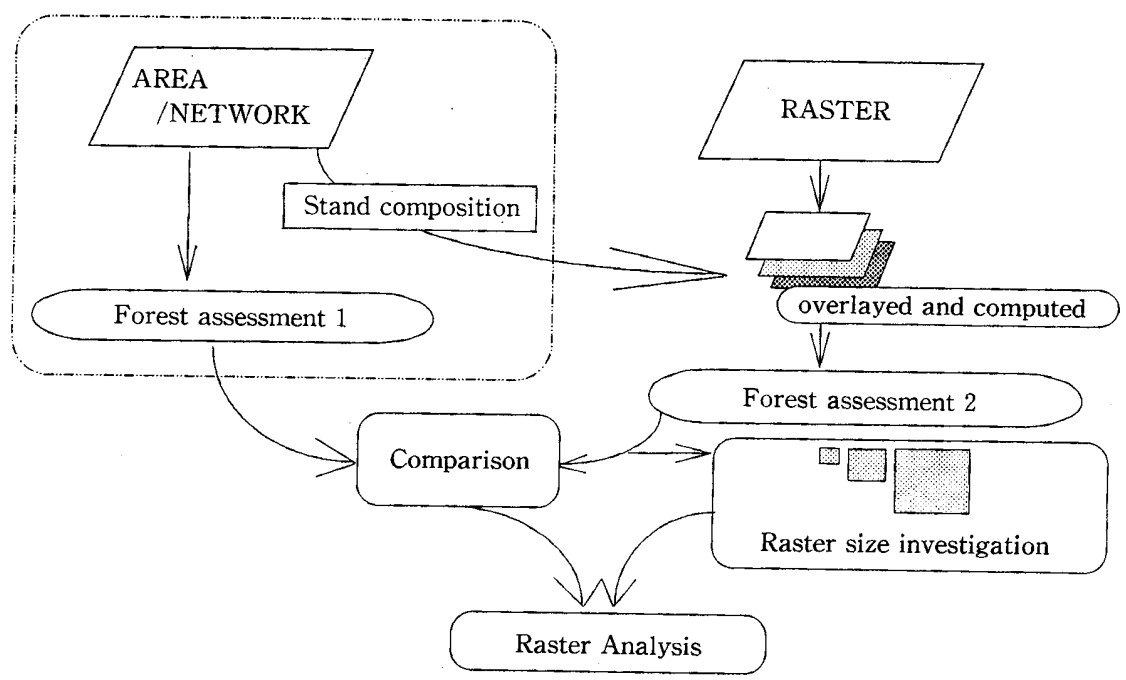

Fig. 1 Analysis flow. 


\section{RESULTS}

Results of Forest Function Evaluation by Each Raster Size

According to the standards shown above, forest functions in each raster size were evaluated and the results shown in Table 1 and Fig. 2. In case of the erosion protection function, together with a larger raster size, classified areas decrease, although in the other functions it was recognized that coupled with size the areas tended to be reduced. The public health and recreational forest function showed the largest fluctuation in raster size, and in a size interval from $10 \mathrm{~m}$ to $50 \mathrm{~m}$, area increased by $65 \%$. In addition, in the erosion protection function $26 \%$ of area reduction was recognized even within the same size.

Table 1 Classification of forest activity

unit: (ha)

\begin{tabular}{lrrr}
\hline Forest activity & size $10 \mathrm{~m}$ & size $20 \mathrm{~m}$ & size $50 \mathrm{~m}$ \\
\hline Timber production & 21.62 & 22.32 & 24.25 \\
Land conservation & 147.95 & 135.32 & 110.00 \\
Recreation & 37.36 & 43.48 & 61.75 \\
Water conservation (Selection cutting) & 14.87 & 16.56 & 18.75 \\
Water conservation (Reserve) & 41.88 & 46.04 & 48.50 \\
non-function & 0.42 & 0.40 & 0.50 \\
\hline
\end{tabular}

Comparison of Forest Function Division with Each Small Sub-compartment Unit

The area increase/decrease ratio to the function evaluation results by each small sub-compartment is shown in Table 2. When a respective function division is compared, the areas in the timber production function, public health and recreational function, and selection cutting water source conservation function increased, and on the contrary, a decrease of areas in the erosion protection function and the reserved water source conservation function was recognized. In the public health and recreational function, an increase from about $250 \%$ to $470 \%$ was recognized, and in the reserved water source function, a decrease from $35 \%$ to $43 \%$ was recognized.

Table 2 Comparison result of classification

\begin{tabular}{|c|c|c|c|c|}
\hline \multirow{2}{*}{ Forest activity } & \multirow{2}{*}{$\begin{array}{l}\begin{array}{l}\text { Result of } \\
(\mathrm{I})^{*}(\text { ha })\end{array} \\
\text { area }\end{array}$} & \multicolumn{3}{|c|}{$\begin{array}{l}\text { Ratio of increase and } \\
\text { decrease }(\%)\end{array}$} \\
\hline & & size $10 \mathrm{~m}$ & size $20 \mathrm{~m}$ & size $50 \mathrm{~m}$ \\
\hline Timber production & 20.61 & 4.90 & 8.30 & 17.66 \\
\hline Land conservation & 143.16 & 3.35 & -5.48 & -23.16 \\
\hline Recreation & 10.82 & 245.29 & 301.85 & 470.70 \\
\hline $\begin{array}{l}\text { Water conservation } \\
\text { (Selection cutting) }\end{array}$ & 14.99 & -0.80 & 10.47 & 25.08 \\
\hline Water conservation (Reserve) & 74.03 & -43.43 & -37.81 & -34.49 \\
\hline
\end{tabular}

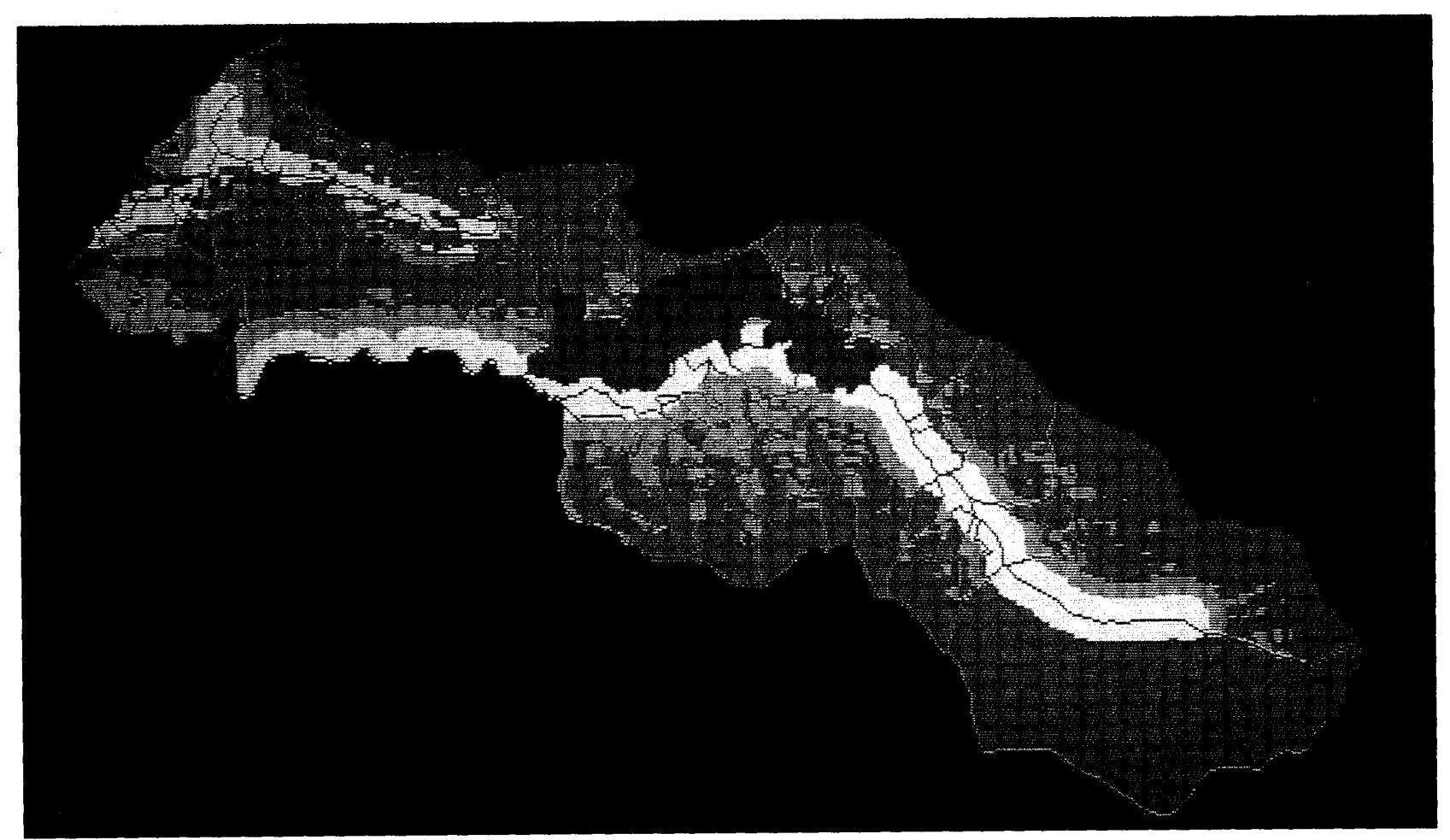

(A)

Fig. 2 Distribution of forest activity classification by each raster size. 


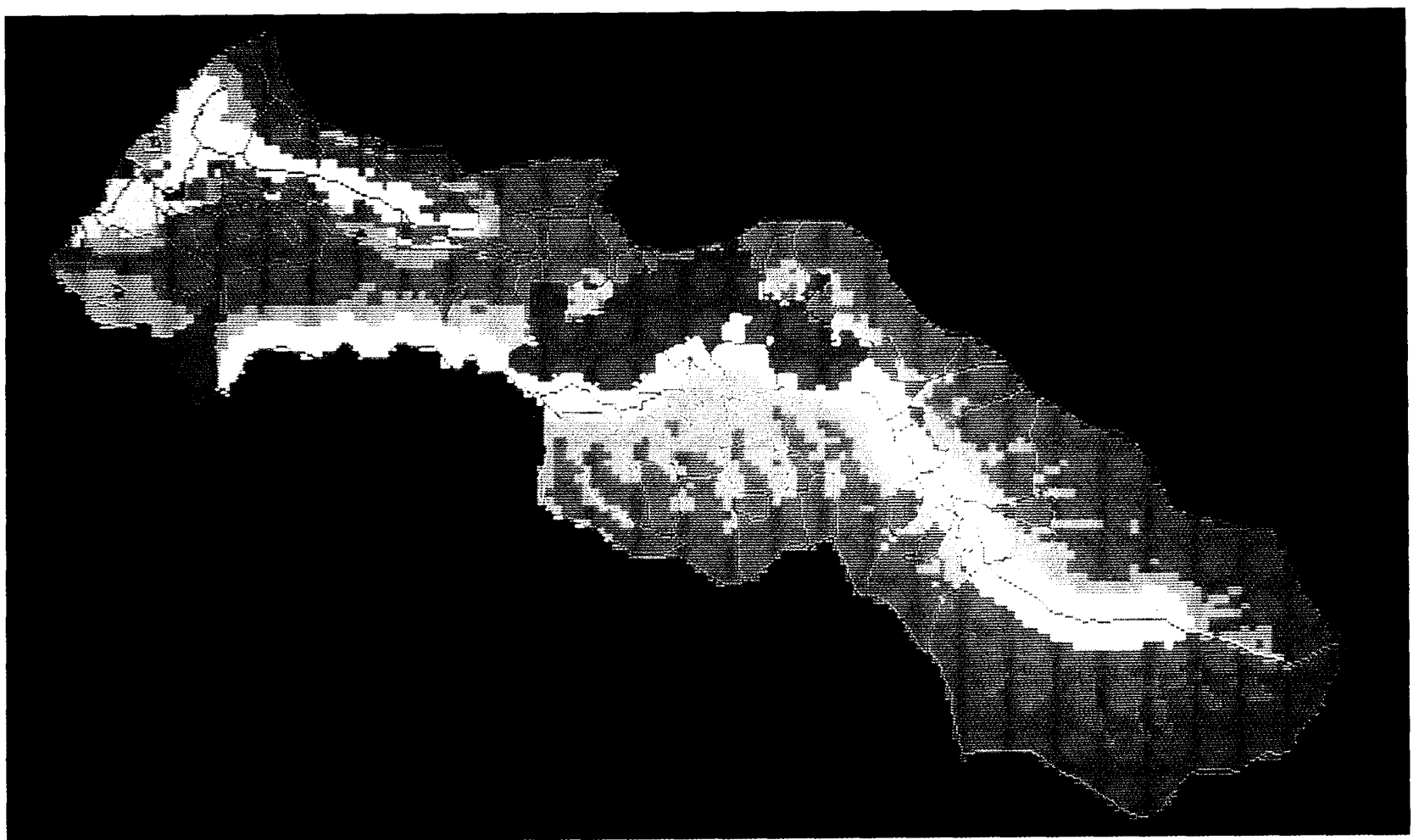

(B)

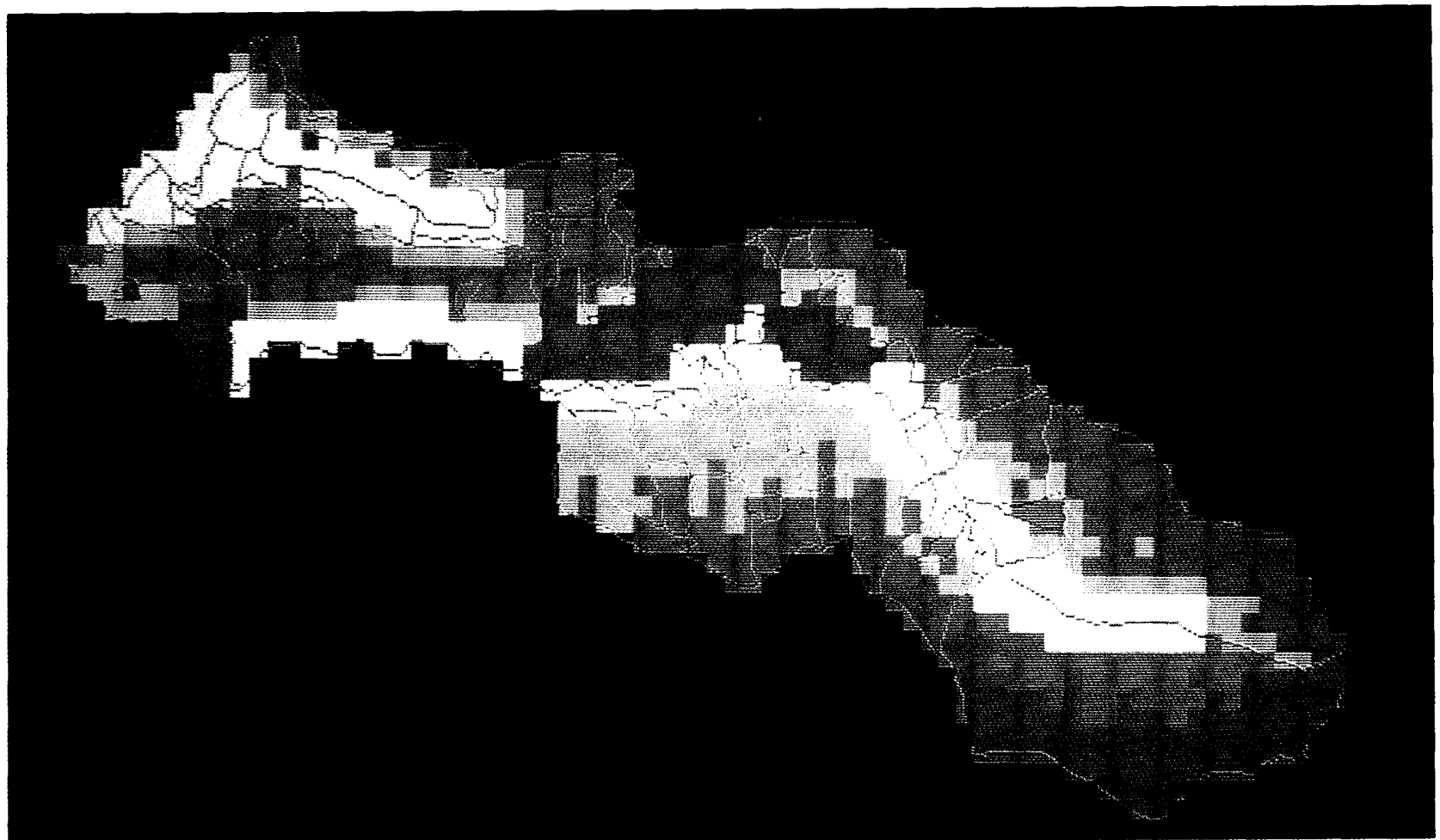

(C)

Fig. 2 Distribution of forest activity classification by each raster size.

(A) ; $10 \mathrm{~m} \times 10 \mathrm{~m},(B) ; 20 \mathrm{~m} \times 20 \mathrm{~m},(\mathrm{C}) ; 50 \mathrm{~m} \times 50 \mathrm{~m}$

Green ; Erosion protection forest, Light blue; Reserved water source conservation forest, Purple ; Selection cutting water source conservation forest, Red ; Timber protection forest, Yellow ; Public and recreation forest The upper indicates north. 


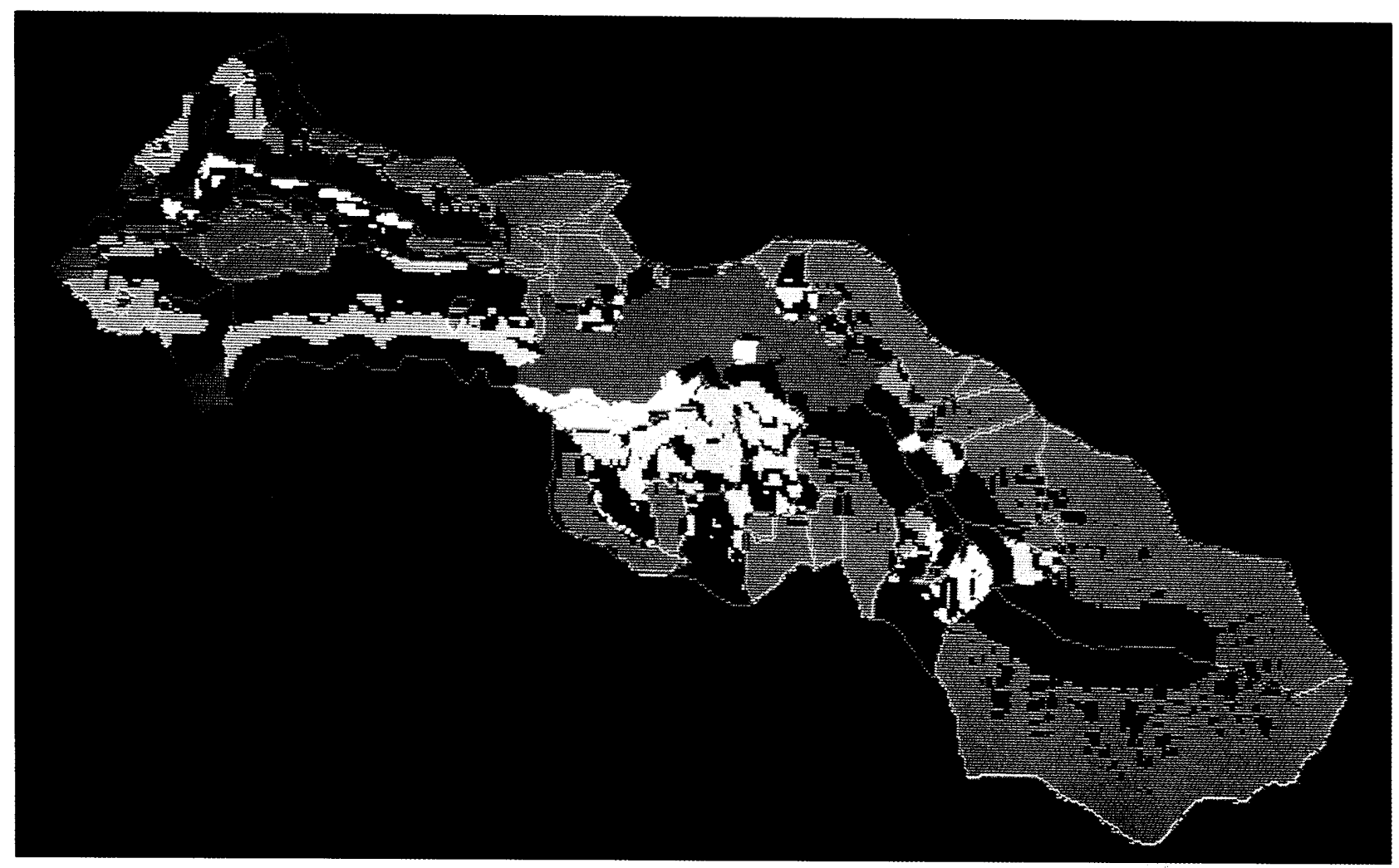

(A)

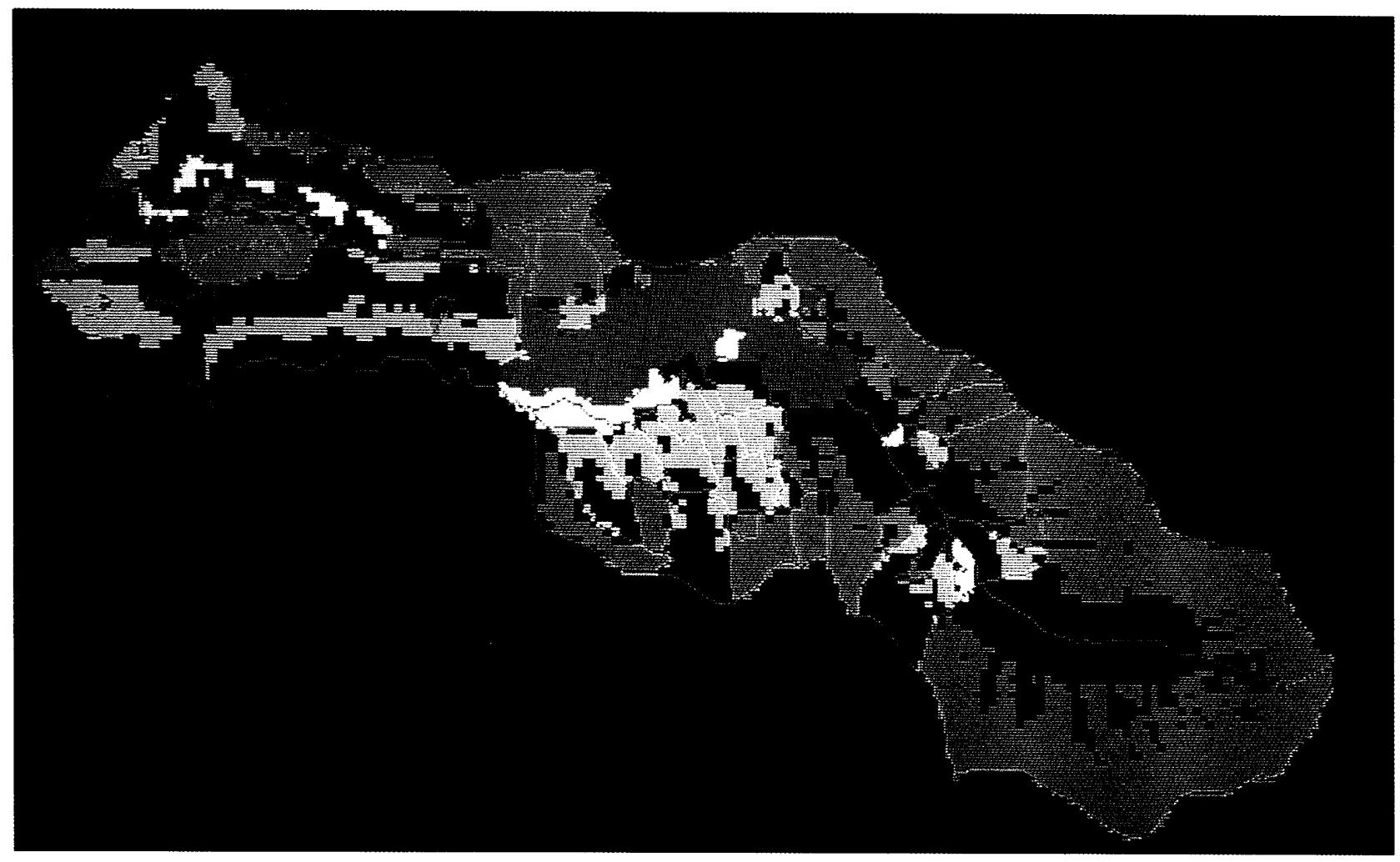

(B)

Fig. 3 Distribution of comparison with forest activity by each sub-compartment unit. 


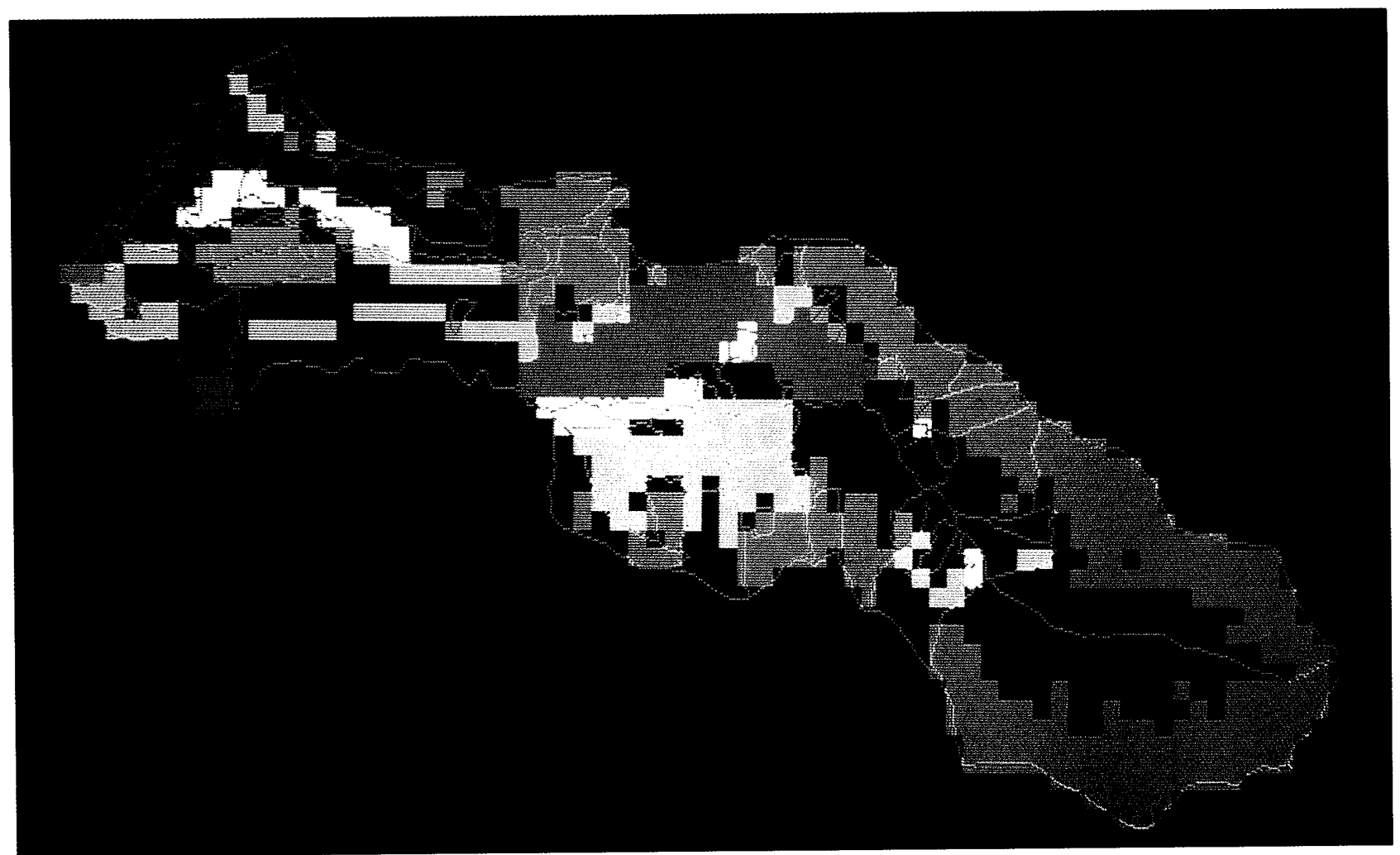

(C)

Fig. 3 Distribution of comparison with forest activity by each sub-compartment unit.

(A) ; $10 \mathrm{~m} \times 10 \mathrm{~m},(B) ; 20 \mathrm{~m} \times 20 \mathrm{~m},(\mathrm{C}) ; 50 \mathrm{~m} \times 50 \mathrm{~m}$

Green ; Erosion protection forest, Light blue ; Reserved water source conservation forest, Purple ; Selection cutting water source conservation forest, Red; Timber protection forest, Yellow; Public and recreation forest The upper indicates north.

Table 3 Overlaid area-func with raster-func

unit: \%

\begin{tabular}{lrrr}
\hline Forest activity & size $10 \mathrm{~m}$ & size $20 \mathrm{~m}$ & size $50 \mathrm{~m}$ \\
\hline Timber production & 90.47 & 89.61 & 85.57 \\
Land conservation & 72.06 & 74.58 & 80.00 \\
Recreation & 16.19 & 16.38 & 17.00 \\
Water conservation (Selection cutting) & 29.12 & 26.33 & 18.67 \\
Water conservation (Reserve) & 62.30 & 62.38 & 57.73 \\
\hline
\end{tabular}

The forest function evaluation map using the raster was laid on the function evaluation map by subcompartment, and the parts where both functions superimpose and match were picked out and subsequently shown in Fig. 3. The area ratio superposed with the function division by each small sub-compartment unit is shown in Table 3. Although a little variation was recognized in the raster sizes, the area from $85 \%$ to $90 \%$ in the timber production function was superposed, and the area from about $55 \%$ to $80 \%$ was superposed in the erosion protection forest and the reserved water source conservation forest.
Conversely, in the case of the public health and recreational forest and the selection cutting water source conservation forest, only the area from about $16 \%$ to $30 \%$ could be superposed compared with other functions, a large difference being seen in the area of function evaluation by 2 methods.

\section{Influence of Raster Size}

In the preceding analysis, a fairly big fluctuation was recognized between the function evaluation results by each small sub-compartment unit and the forest function evaluation results by the rasters, and in addition between the raster sizes. It is presumed that this is due to the magnitude of raster sizes.

The site merit information used in this report, namely information on the forest roads, ridges, water systems and stands was obtained by converting vector data to raster data. By using a small sub-compartment, the error in the case of raster conversion was shown in Table 4 using verification statistics. Along with smaller raster size, it is recognized that a statistic approximates to 0 , and conver- 
Table 4 Accuracy overlaid vector with raster

\begin{tabular}{llll}
\hline & size $10 \mathrm{~m}$ & size $20 \mathrm{~m}$ & size $50 \mathrm{~m}$ \\
\hline max error (ha) & 0.09 & 0.17 & 0.57 \\
min error (ha) & 0 & 0 & 0.01 \\
statistic & 0.028 & 0.124 & 2.451 \\
\hline
\end{tabular}

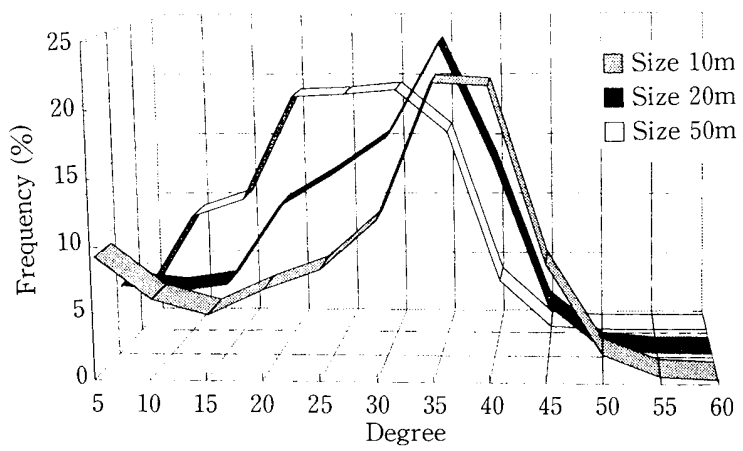

Fig. 4 Frequency distribution for slope each raster size.

sion error from the vector data become smaller. Thus, conversion of the vector data, together with a smaller raster size will increase accuracy.

Inclination angle, topographic information, and distribution of inclination angle by each raster size appears in Fig. 4. Accompanied by an increase in raster size, it is seen that distribution of the inclination angle tends to be shifted towards a flatter slope direction. The elevation value is thinned out in a constant ratio when the values are distributed at random, it is then removed and smoothed so that a large portion of slope variation is given for two points. It is thought that the variation occurs because slope based on height difference for two points is averaged and gentled(KITAGAWA 1991). By $\chi^{2}$ verification, it was signified that the distributions of inclination angle between the various raster sizes are different $\left\{\chi^{2}=455.886>\chi^{2}{ }_{0}(\phi\right.$ $=22, \alpha=0.05)\}$. In function classification in this report, inclination angle is an important factor. It was presumed that a cause which exerted a substantial influence on the classification results was the fluctuation of the distribution on inclination angle by each raster size.

\section{DISCUSSION}

Comparison of Forest Function Evaluation by Small Subcompartment Unit and Raster Unit

As shown in Table 2 and Table 3, the areas of the evaluated forest function division varied greatly depending on the raster sizes. Of these, area differences of a maximum of 4.7 times especially in the public health and recreational function, and of a maximum of 0.4 times in the selection cutting water source conservation function were recognized. In addition, from Fig. 3 the plural function area seen in 1 small sub-compartment, and, consequently, a distribution difference from the evaluation results by each subcompartment unit can be understood. These are different from the function evaluation by each small subcompartment unit which adopted the average inclination angle, and are the results expressing in detail topographic information using rasters. Apart from the standardized function evaluation by each small sub-compartment, it is shown that function evaluation corresponding to a topography is possible after considering the information of the stand, site merit and topography.

\section{Function Evaluation by Raster}

In the function evaluation by each small subcompartment unit and the function evaluation by raster, the evaluation results were different depending on the functions, and in addition, coupled with an increase in raster size, the areas of function evaluation division by raster increased and decreased. The functions with little variation in area are the timber production forest and selection cutting water source conservation function. These functions are strongly affected by the factors except for the topographic factors in the function classification process. Therefore, an increase/decrease difference compared with the function evaluation by each small sub-compartment unit will become minimum in a $10 \mathrm{~m}$ size raster with little conversion error in vector data. As for the timber productin function, it can be judged that distribution will not change from Fig. 3. As for the erosion protection function, the fact that there was a significant difference between function evaluation by each small sub-compartment unit and vector information in function evaluation by raster, may be given as a reason. Since the degree of dependence on the vector is high in the case of the 3 functions mentioned above, it is thought that many vector conversion errors are contained in the variations between rasters. On the contrary, in the public health and recreational function and reserved water source conservation function, because the classification is performed depending on topographic data rather than vector data, the area difference from the evaluation by each small sub-compartment unit increased. Therefore, it is considered that conversion of the vector data has an important significance in function evaluation by raster unit.

As for the variations between rasters, in addition to the conversion errors of vector data, the inclination angle distribution by the raster sizes also exerts an influence. This affects each function, except the timber production function. In the erosion protection function, classified as having an inclination angle exceeding $30^{\circ}$, a division area 
decreases accompanied by an increased size, and it increases in the other functions classified as less than $30^{\circ}$. This is the same tendency shown by inclination distribution by raster size (Fig. 4). This means that forest function evaluation corresponding to topography is possible using the detailed raster type data.

\section{Optimum Raster Size in Function Evaluation}

Based on the function evaluation results by the raster sizes, it was considered that an increase/decrease of each function division area is caused by a loss of vector information (Table 4) by a change of sizes, as well as the influence of increasing distribution of the flatter slopes (Fig. 4) proportional to the raster sizes. Accordingly, the raster size will be a big point at issue in function evaluation. Concerning the conversion accuracy of vector information, a convenient rule of thumb, based on statistical sampling theory, is to use a raster cell half the length (or one-fourth the area) of the smallest feature one wishes to record. A more conservative suggestion would be to use a raster size one-third or one-fourth the length of the smallest desired feature (STAR and EsTES 1990). As for the optimum raster size for function evaluation, based on the conversion accuracy of vector information, estimated results of inclination angle and so on, it was considered that a size of $10 \mathrm{~m} \times 10 \mathrm{~m}$ was suitable for forest function evaluation corresponding to topography at this stage.

\section{CONCLUSIONS}

The purpose of this report was to evaluate forest function by raster unit. When forest function in one small sub-compartment was evaluated by raster unit, it separated into many forest functions. This shows that a function evaluation corresponding to more detailed topography which could not be expressed by a small sub-compartment unit is possible. In future, it is necessary to investigate further methods of deciding raster size corresponding to the various topographies.

\section{ACKNOWLEDGMENTS}

We are deeply indebted to Prof. Dr. Shogo Kobayashi of Niigata Univ. for his advice and helpful suggestions. For the use of Terra Soft, the authors wish to express their appreciation to Mr.Kouji OHIwA of the Visual Science Co. LTD.

\section{LITERATURE CITED}

Abe, N., Kamioka, H. and Benitani, R.,(1995): Forest activity classification system for small watershed area using GIS( I ) Classification system in case of sub-compartment. J. For. Plann. 1 :7-14

Aronoff,S., (1989): Geographic information systems: A Management Perspective. WDL Publications, Ottawa, 166pp

Essential Planning Systems Ltd., (1992): Terra Soft DTM Reference Guide : $42-44$

KitAGAWA,K.,(1991): Fundamental studies on the terrain analysis in mountainous forest areas. Reprinted from the Bulletin of the Nagoya University Forest 11: 133pp

STAR,J. and Estes,J., (1990): Geographic information systems: An introduction. Prentice-Hall Inc., 37pp

(Received 6 April 1995)

(Accepted 30 June 1995) 